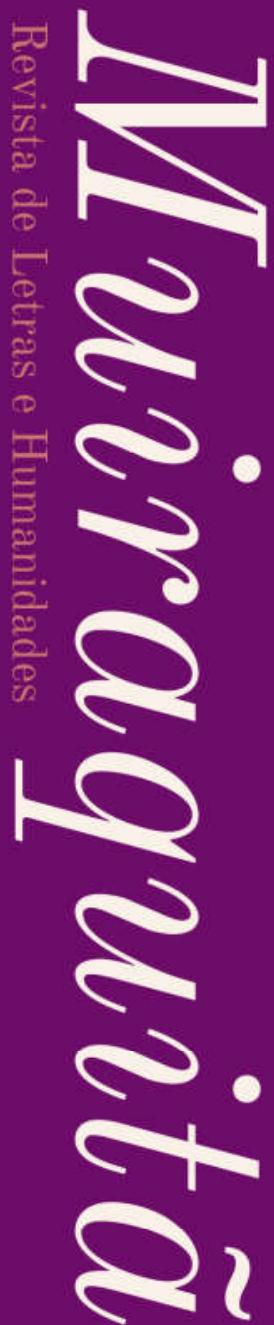

\title{
Comentários em uma página da rede social Instagram: reflexões situadas de uma prática discursiva on-line
}

\author{
Diêgo Martins da Costa \\ Universidade Estadual de Goiás \\ diegomartcosta@gmail.com \\ https://orcid.org/0000-0002-9287-9539 \\ Paulo Almeida de Oliveira Junior \\ Universidade Estadual de Goiás \\ pjcristo@hotmail.com \\ https://orcid.org/0000-0002-1756-7893 \\ Hélvio Frank Oliveira \\ Universidade Estadual de Goiás \\ helviofrank@hotmail.com \\ https://orcid.org/0000-0002-0553-8075
}

RESUMO: Considerando o comentário on-line como uma prática social sem precedentes em nossa contemporaneidade, eminentemente linguística, este artigo busca perscrutar os significados mobilizados em comentários motivados a partir da divulgação de uma notícia em uma página jornalística no Instagram, observando criticamente a prática discursiva e suas implicações no e para além do contexto virtual. Para a análise discursiva crítica do corpus obtido em plataforma virtual, fundamentamo-nos no gênero comentário on-line (CUNHA, 2012; ENTRINGER, 2018; SAL PAZ, 2013; SANTOS, 2018), em documentos oficiais que regem sobre os Direitos Humanos (ONU, 1948; BRASIL, 2014) e em perspectivas críticas de linguagem (AUSTIN, 1990; BARTON, 2009; FAIRCLOUGH, 2001, 2006). Os resultados indicam a produção e manutenção de textos/discursos coloniais que reiteram práticas discriminatórias sobre pessoas em vulnerabilidade social. Nesse sentido, apontamos para a urgência de criticidade sobre as práticas de comentar on-line.

PALAVRAS-CHAVE: Educação linguística crítica. Prática discursiva virtual. Direitos humanos. Gênero comentário on-line.

\section{COMMENTS ON AN INSTAGRAM SOCIAL NETWORK: REFLECTIONS FROM AN ONLINE DISCOURSE PRACTICE}

ABSTRACT: Considering online commentary as an unprecedented social practice in our eminently linguistic contemporaneity, this article seeks to scrutinize the meanings mobilized in comments motivated by the release of a news story on a journalistic page on Instagram, critically observing the discursive practice and its implications in and beyond the virtual context. For the critical discursive analysis of the corpus obtained on a virtual platform, we based ourselves on the online comment genre (CUNHA, 2012; ENTRINGER, 2018; SAL PAZ, 2013; SANTOS, 2018), in official documents governing Human Rights ( UN, 1948; BRAZIL, 2014) and in critical perspectives of language (AUSTIN, 1990; BARTON, 2009; FAIRCLOUGH, 2001, 2006). The results indicate the production and maintenance of colonial texts/discourses that reiterate discriminatory practices against people in social vulnerability. In this sense, we point to the urgency of criticality regarding online commenting practices.

KEYWORDS: Critical linguistic education. Virtual discursive practice. Human rights. Online comment genre. 


\section{CONSIDERAÇÕES INICIAIS}

Com o advento da Internet e, consequentemente, com um número crescente de acessibilidade de seus usuários no Brasil, conforme divulgado na pesquisa TIC Domicílios $2019^{1}$, as práticas sociais vivenciadas na esfera tecnológica têm cada dia mais se reformulado e, com isso, alcançado novas e diferentes formas de comunicação. Diante das oportunidades digitais, diversos gêneros discursivos e seus arranjos se reconfiguram em meio às práticas virtuais. Em contexto de pandemia, em que se recomenda o isolamento físico como medida sanitária frente ao combate à Covid 19, as relações sociais nos são possibilitadas exclusivamente devido à facilidade de dispormos das telas mais vistas em nosso cotidiano: a do computador, do smartphone ou de outros aparelhos móveis conectados à Internet.

Nas redes sociais, por exemplo, por sinal muito aderidas por brasileiros, as interações operam sob aspectos discursivos, sobre os quais, se levados à criticidade, poderíamos refletir de maneira educativa, com vistas a questionar sobre que tipos de práticas sociais estamos re/produzindo no mundo on-line. Na rapidez e praticidade de um clique, na dinamicidade global de acesso a outras culturas, pessoas, ideologias, visões de mundo, dizeres, narrativas etc., somadas ao desejo humano da comunicação, o que estamos fazendo virtualmente?

A esfera virtual envolve relacionamento social entre internautas, por essa razão é constituída de negociações e propagações de sentido pautadas em diversas relações de poder, mediadas por diferentes manifestações de linguagem. Logo, é discursiva por estabelecer uma arena em que o digitar e o postar promovem materialidades constitutivas de significados lançados à rede, por tabela, enunciadores do que é imaginariamente celebrado em sociedade. Isso ocorre porque, em referência a Austin (1990), o dizer faz e, acrescentando Barton $(2009$, p. 48), "textos agem como artefatos culturais - como agentes com apoiadores".

O comentário on-line é uma prática virtual sem precedentes. Ao nos conectarmos com a tecnologia digital, comentar é quase um impulso naturalizado. Dentro da esfera jornalística, os estudos de Cunha (2014) e de Santos (2018) observam que a estrutura do gênero se assemelha a uma carta de leitor. Entretanto, inova na medida que se torna mais imediato, devido à acessibilidade síncrona da ferramenta tecnológica. Em comparação à carta de leitor, podemos prever que o comentário on-line não consegue sofrer monitoramento em termos do conteúdo veiculado por parte da equipe editorial, e, embora haja a opção de excluir comentário, não é muito comum ao administrador da página jornalística apagar tais enunciados, ficando a leitura e a escrita de comentários mais dinâmicas e democratizadas.

À luz de perspectivas textual-discursivo-críticas (FAIRCLOUGH, 2001, 2006; BARTON, 2009; BORBA, 2014; MAGALHÃES, 2017), neste texto buscamos perscru-

1 A pesquisa sobre o uso das tecnologias de informação e comunicação nos domicílios brasileiros 2019 foi realizada pelo Centro Regional de Estudos para o Desenvolvimento da Sociedade da Informação (Cetic.br), vinculado ao Comitê de Gestão de Internet no Brasil, e traz levantamentos sobre o acesso a tecnologias da informação e comunicação. O estudo mostra que 3 , em cada 4 usuários no Brasil, possuem acesso à Internet, o que corresponde a 134 milhões de pessoas no Brasil, e esse acesso é geralmente viabilizado pelo smartphone. 
tar os significados mobilizados em comentários, motivados a partir da divulgação de uma notícia em uma página jornalística no Instagram, observando criticamente a prática discursiva e suas implicações no e para além do contexto virtual. Nas próximas seções, discutimos o comentário on-line na condição de texto que, na perspectiva de Fairclough (2001), materializa práticas discursivas e sociais, e vice-versa, problematizando a urgência de criticidade ao comentar em plataformas digitais. Em seguida, apresentamos os procedimentos metodológicos, para, finalmente, analisarmos o contexto enunciativo de uma prática situada.

\section{O GÊNERO TEXTUAL/DISCURSIVO 'COMENTÁRIO ON-LINE'}

O comentário diz respeito a um gênero antigo, ao mesmo tempo recorrente em diversas esferas comunicativas, dinâmico em caracterizações, além de se fazer bastante usual nas práticas sociais contemporâneas, especialmente nas virtuais. Sua sequência textual é marcada por ideias argumentativas que têm por finalidade tecer avaliação ou emitir opinião sobre um evento textual/discursivo anteriormente apresentado. Para Köche et. al. (2017), sua estrutura é relativamente livre, a depender das intenções e circunstâncias pragmáticas envolvidas no ato.

Na esfera de comunicação on-line, segundo Sal Paz (2013), em geral, o comentário torna-se materializado na modalidade escrita e, em algumas vezes, conta com procedimentos multimodais e com recursos de hipertexto. Evidencia-se textualmente por seu caráter subjetivo, instável, coloquial, original, criativo e, especialmente, pela brevidade e condensação. Sua função comunicativa predominante é a conativa, com vistas a convencer - e acrescentamos: demarcar-se diante de - um destinatário explícito ou leitor universal "mediante estratégias argumentativas de interação" (p. 167).

Ao trazer notas sobre um dos procedimentos de controle do discurso, Foucault (2012) evidenciou que o comentário demanda motivação discursiva anterior, isto é, possui como referência, análise ou apreciação um texto fonte. Nas palavras de Cunha (2012, p. 28), corresponde a

uma prática discursiva que tem o seu propósito e suas regras: a partir de um texto fonte, o leitor constrói novos discursos, reacentuando diferentemente os aspectos temáticos, os sentidos múltiplos, explícitos ou subentendidos, ou introduzindo deslocamentos e mudanças de temas em função do seu PDV [ponto de vista]. (CUNHA, 2012, p. 28)

Para Foucault (2012, p. 22), o comentário cria deslocamentos que vão desde "discursos fundamentais ou criadores" a uma "massa daqueles que repetem, glosam e comentam". Nessa dispersão, cuja função e reposição em jogo nunca cessam, promovendo o que o autor chama de desnível entre o texto fonte e os outros que dele partem, "[m] uitos textos maiores se confundem e desaparecem, e, por vezes, comentários vêm tomar o primeiro lugar". Isso alimenta o fato de que a linguagem mobilizada no comentário possui força agenciadora (MAGALHÃES, 2017). Assim, a prática social em torno do comentário reflete cosmovisão interlocutória, ao mesmo tempo em que abre oportunida- 
de para o surgimento de novas apreciações, de modo a, ciclicamente, abastecer o tema e, a partir dos assuntos que o envolvem, motivar outros.

Uma característica relevante sobre o comentário on-line, na concepção de Santos (2018), é sua ampla cadeia de enunciados. Nesse movimento inter e perlocutório, comentadores podem eleger um destinatário presumido e responder a um interlocutor coletivo. Em analogia foucaultiana, no contexto virtual o desnível entre um comentário e outro desempenha um papel solidário, no sentido de construir, ainda que indefinidamente, novos discursos. Contudo,

[o] fato de o texto primeiro pairar acima, sua permanência, seu estatuto de discurso sempre reatualizável, o sentido múltiplo ou oculto de que passa por ser detentor, a reticência e a riqueza essenciais que lhe atribuímos, tudo isso funda uma possibilidade aberta de falar. Mas, por outro lado, o comentário não tem outro papel, sejam quais forem as técnicas empregadas, senão o de dizer enfim o que estava articulado silenciosamente no texto primeiro. Deve, conforme um paradoxo que ele desloca sempre, mas ao qual não escapa nunca, dizer pela primeira vez aquilo que, entretanto, já havia sido dito e repetir incansavelmente aquilo que, no entanto, não havia jamais sido dito. A repetição indefinida dos comentários é trabalhada do interior pelo sonho de uma repetição disfarçada: em seu horizonte não há talvez nada além daquilo que já havia em seu ponto de partida, a simples recitação. (FOUCAULT, 2012, p. 24, grifos do autor)

Em contexto virtual, quem comenta está à mercê de um retorno. Ainda que a bolha do isolamento virtual permita ao comentador figurar o caráter individualista de uma postagem, é comum que o apreciador do comentário coce os dedos para dar um like ou digitar uma resposta, corroborando a noção cíclica em relação ao texto fonte. Daí por diante, a relação entre comentários nos fornece pistas para pensar a dinâmica intergêneros, envolvendo uma rede de acontecimentos sob um contexto de enunciação mais amplo: o debate. São dinâmicas as formas de ocorrência do comentário no Instagram: pode aparecer como resposta dentro da própria caixa de comentário-referência, pode se constituir como uma resposta direcionada indiretamente a outro comentário realizado, utilizando-se outro espaço, pode ainda ser usado para chamar terceiros à apreciação por intermédio do recurso de linkar o perfil pessoal ao comentário etc.

Quando se observa um volume de comentários, podemos entender que o emaranhado ali - a partir do qual se pressupõe o debate - gera uma rede de significados, de enunciação que possui uma espécie de relação entre si ou com algumas de suas partes. Para além disso, como explica Santos (2018, p. 29),

[n]o meio digital, essa noção de interlocutor imediato e interlocutor genérico vai ao encontro da relação entre o público e o privado, visto que, ao mesmo tempo em que o meio favorece a interação direta entre um "eu" e um "tu", como se ambos conversassem num tempo e lugar comum, simulando um diálogo face a face (espaço privado), é dado a terceiros o acesso a esse diálogo (espaço público). Então, aquela suposta interação que parece ser particular de dois falantes ou de um grupo, também, faz parte de um processo interativo mais amplo, visto que os leitores desse gênero também passam a ser destinatários. 
Diante dessas condições, uma vez produzido, o comentário se alia a uma cadeia de enunciados, ou seja, a ditos em resposta a um texto referência - também já dito. Ao mesmo tempo, aciona diferentes movimentos perlocutórios já listados por Entringer (2018), como: adesão, refutação, apoio, crítica, ironia, questionamento. Além disso, a possibilidade de comentar algo no jornalismo virtual, de acordo com Santos (2018, p. 27), enriquece "o potencial informativo (crítico-analítico) da notícia" em mídias digitais, na medida que o comentador aparece como produtor de conteúdo, de maneira a fornecer informações não contempladas na notícia, seja para "divergir, convergir ou complementar uma afirmativa proposta" (ENTRINGER, 2018, p. 24). Independentemente do pretexto e da validade do argumento, voltando a Santos (2018, p. 27), essa apreciação também acaba por influenciar o ponto de vista de outros leitores.

O ponto fulcral é que a "reação-resposta", nessa dinâmica fluida de comentar um texto jornalístico on-line, nos faz perceber que o meio ideológico a envolver os internautas interlocutores constitui-se bem mais amplo do que o domínio discursivo que circula sobre o próprio texto-comentário, o que nos alerta para o contínuo das interações sociais e das ideologias produzidas em dado contexto.

\section{CRITICIDADE SOBRE AS PRÁTICAS DE COMENTAR ON-LINE}

Em relação ao comentário on-line em redes sociais, algumas convenções parecem ser compactuadas pelos usuários ao se inserirem no gênero. Em uma espécie de etiqueta virtual, se o comentário vier em forma de 'textão', certamente não será lido. Outra convenção nada proveitosa na contemporaneidade, em determinadas plataformas de rede social, é a prática de comentários que veiculam discursos de ódio (CINTRA, 2012; BIAR, 2020; MERCURI, LIMA-LOPES, 2020) e violência linguística (SILVA, 2019). Se a Declaração Universal dos Direitos Humanos (ONU, 1948), por exemplo, em seu Art. XIX, garante-nos o direito de expressar opiniões em qualquer meio de comunicação, é salutar que reflitamos sobre nosso comentar, a fim de que construamos uma cultura de postagem empática, ética e menos agressiva entre internautas.

Essas condições nos remetem ao fato de que a prática discursiva do comentário se articula a atos de criação linguística, ou mesmo evidenciam o protagonismo da linguagem (MAGALHÃES, 2017). Comentar por comentar, mais do que resultar e ser resultado de indignação, conivência ou conveniência, molda a estrutura discursiva promulgadora da realidade socialmente construída, corroborando a manutenção de determinadas estruturas prejudiciais à vida humana (BIAR, 2020). É nessa dinâmica das relações virtuais, eminentemente sociais, que os significados e efeitos dos discursos produzidos denotam a estrutura social forjada, ao mesmo tempo que podem se resultar dela.

Magalhães (2017) argumenta que a linguagem e os textos possuem força agenciadora. Para a autora, eles carregam

o poder de produzir significados e evocar lembranças; a portabilidade no tempo, no espaço e no contexto; a durabilidade; e os efeitos causais, chamando atenção 
para determinados aspectos do mundo social e construindo identidades. (MAGALHÃES, 2017, p. 585)

A criticidade em relação à prática discursiva de comentários on-line muito nos interessa, por remeter à qualidade agenciadora desse tipo de texto (AUSTIN, 1990; FAIRCLOUGH, 2001, 2006; MAGALHÃES, 2006). Foucault (2012, p. 24) salienta sobre o potencial acional discursivo do comentário ao informar que esse "conjura o acaso do discurso fazendo-lhe sua parte: permite-lhe dizer algo além do texto mesmo, mas com a condição de que o texto mesmo seja dito e de certo modo realizado".

Assim sendo, ainda que não reconheçamos o corpo-político de quem reage linguisticamente em referência a um texto, talvez porque o perfil não seja público ou talvez porque o comentador utilize do artifício de anonimato para comentar ou, em alguns casos, para agredir o outro com palavras, as relações intersubjetivas sempre demarcarão poder, disputas ideológicas e mundividência; colaborarão, portanto, com a cosmovisão. Isso acontece porque "o novo não está no que é dito, mas no acontecimento de sua volta" (FOUCAULT, 2012, p. 25). Afinal, voltando em Magalhães (2017), os textos podem atuar à medida que são compreendidos "em relação às práticas sociais e aos discursos específicos em que se situam". Nisso consiste o protagonismo da linguagem.

Em tela, o poder exercido pelo comentador emana de suas ações discursivas balizadas pela identidade virtual que possui, mesclado a sua quantidade de seguidores, ao compartilhamento do comentário postado, à marcação de usuários, por meio de @ nomedousuário, indicando a matéria do comentário a terceiros, à manifestação repetida do apoio em forma de curtida ou de congratulações de outros usuários, entre outras formas. Todo esse efeito perlocutório embrenha dinâmicas discursivas que vão desde a consequência de alimentar, de maneira sadia, o debate, até mesmo à exposição pública e negativizada de algum envolvido, causando-lhe opressão.

Por todas essas razões, há urgência em criticidade para usarmos as redes sociais e, especialmente, nos precavermos do conteúdo de nossa postagem, considerando leis que orientam sobre o uso da Internet (BRASIL, 2014) e os direitos humanos (ONU, 1948), sob pena de cometermos crimes digitais, a depender do comentário que realizamos e a partir do que essa ação mobiliza e no que repercute. Dispor-se de determinado discernimento equivale reconhecer que, de acordo com Fairclough (2001, p. 91), "o discurso contribui para a constituição de todas as estruturas sociais, direta ou indiretamente". Configura-se como uma prática "não apenas de representação do mundo, mas de significação", ou seja, uma prática que constrói o mundo em significado.

\section{CONTEXTO E CONTEXTUALIZAC̣ÃO DA PESQUISA}

Este estudo versa sobre as práticas discursivas, incluindo seus efeitos de significado em circulação no ciberespaço. Para tanto, fundamentamo-nos nos princípios de uma análise crítica do discurso (FAIRCLOUGH, 2001, 2006; RESENDE; RAMALHO, 2019) produzida em/para o digital, observando a ação e a representação discursiva por intermédio dessa prática social. Nossa opção de suporte se deu pela escolha da platafor- 
ma digital Instagram, uma rede social contemporânea caracterizada pelo grande fluxo de publicações diárias.

Dentro dela, selecionamos uma página de jornal on-line com grande visualização de postagens em contexto goiano e ponderada sob o critério de existência de uma notícia mais recente envolvendo o tema "agressão policial". O corpus cumpria à época de sua seleção, em janeiro de 2021, tal requisito, e nos serviu para abordar, em paralelo, um tema corriqueiro e que ainda carece de debates no estado de Goiás: a ação policial.

Metodologicamente, nossas análises têm como foco os usos linguísticos contextualizados de internautas que interagem, isto é, os significados discursivos detidos a partir de uma notícia postada na página. Segundo Borba (2014, p. 20, grifos no original), essas dinâmicas "sócio-histórico-discursivas" fazem que "ao falarmos/escrevermos X, Y ou Z sejamos percebidos/as como A, B ou C", o que, para o autor, equivale a recursos linguísticos (e identitários), "produtos de processos históricos, políticos, filosóficos e culturais específicos e sua utilização nos insere nessas dinâmicas".

Qualitativamente, discutimos os principais significados perseguidos em torno dos comentários, levando-se em consideração o texto fonte, por sua vez materializado por 1) uma imagem/fotografia - da mulher protagonista da trama - que estampa a lide, seguida de 2) a notícia escrita em língua portuguesa assinada por um redator e postada na página da rede social administrada pelo jornal, bem como seu contexto enunciativo. Os comentários referem-se à notícia publicada e/ou a outros comentários nas formas de réplica e tréplica, formando uma espécie de debate.

Além disso, sob análise dos turnos da conversa, porque em muitos casos os comentários reivindicaram a tipologia do diálogo, foi possível evidenciar algumas proporções, números e porcentagens subsidiadas por aspectos quantitativos do debate, suplementando a análise discursiva. Por essas razões, analisaremos, nos excertos, se o comentário é direto $(\mathrm{CD})$ ou indireto $(\mathrm{CI})$ e a que corpo-político pertence sua autoria: se masculino (M), feminino (F) ou anônimo (A).

\section{UMA INTERPRETAÇÃO DO MATERIAL EMPÍRICO}

A página midiática selecionada está hospedada na rede social Instagram e divulga acontecimentos sobre/em o Brasil e o mundo, com ênfase em fatos ocorridos no estado de Goiás. Possuía, à época da geração do corpus, acima de 900 mil seguidores. Em seu histórico de página, divulga fatos voltados à esfera jornalística e configurados como notícias e reportagens. A notícia que aciona os comentários a serem analisados estampa a semiose da mulher que protagonizou a trama informada, apresenta a lide "Policiais militares são denunciados por morte de confeiteira em Inhumas" e vem assinada por um redator na data de 4 de janeiro de 2021. Geram-se, a partir da postagem, 5.096 curtidas e, apesar de serem informados 253 comentários, foi possível acessar a leitura de apenas 223 deles, conforme última verificação para análise.

No corpo da notícia publicada, que servirá como texto fonte gerador dos comentários, é informado que 
O Ministério Público de Goiás (MP-GO) denunciou dois policiais militares de Goiás pela morte da confeiteira Fabiana Matos Rodrigues, de 23 anos, ocorrida em outubro do ano passado, em Inhumas. Na denúncia, o MP-GO alega que o subtenente Alcir da Silva Lima e o soldado Ricardo de Jesus Souza, indiciados pela Polícia Civil, mataram Fabiana com "recurso que dificultou a defesa da vítima" na frente de seu filho de 6 anos, além de tentarem matar, também sua prima, de 16 anos, que saiu ferida.

O caso ocorreu na noite de 8 de outubro de 2020, em Inhumas, região metropolitana de Goiânia. Segundo a denúncia de homicídio e tentativa de homicídio, que entrou no sistema da Justiça no dia 15 de dezembro pelo promotor Mário Henrique Cardoso Caixeta, os militares utilizaram recurso que dificultou defesa da vítima "pois elas foram abordadas de surpresa, por viatura policial que já as aguardava no local do evento".

Segundo a assessoria do Tribunal de Justiça de Goiás (TJ-GO), o recesso forense segue até o dia 6 de janeiro, mas mais de 100 juízes plantonistas foram convocados para atuar nesse período. No entanto, até esta segunda-feira, dia 4 de janeiro, a denúncia ainda não havia sido analisada por nenhum juiz.

O Mais Goiás entrou em contato com a Polícia Militar sobre o caso da denúncia contra os PMs e aguarda um posicionamento.

Morta na frente do filho, conforme relatado pelo Ministério Público, Fabiana foi morta no dia 8 de outubro, por volta das $22 \mathrm{~h}$, na rua 28 do setor José Antônio Ferreira, em Inhumas. A mulher teria ido com a prima e o filho de 6 anos em um veículo modelo Parati buscar uma encomenda nas proximidades de um colégio. A encomenda se tratava de 5 tabletes de maconha.

Em seguida, Fabiana e os outros dois ocupantes do carro seguiram para outro local onde encontrariam o comprador da droga. No entanto, ainda segundo o MP-GO, foram surpreendidos pela viatura ocupada por Alcir e Ricardo, que já as aguardavam no local.

Segundo a denúncia, os militares emparelharam com o carro de Fabiana e, sem aviso, começaram a atirar. O órgão relata que a mulher ainda teria gritado que havia uma criança no carro, mas os disparos não cessaram.

Assinado pelo redator do jornal.

A notícia informa que uma confeiteira de 23 anos e 2 menores, filho e sobrinha, de 6 e 16 anos, respectivamente, foram abordados, resultando em um homicídio e uma tentativa de homicídio, sem que as vítimas tivessem condições de defesa. Assim, o redator localiza as pessoas envolvidas, as quais, pela Declaração Universal dos Direitos Humanos (ONU,1948), no artigo XI, inciso 1, são presumidas inocentes até que sua culpabilidade tenha sido provada, de acordo com a lei e por meio de julgamento público, com todas as garantias de defesa.

Apesar de estar com uma quantidade de entorpecentes que pode ser considerada como tráfico, em momento algum a notícia classifica a confeiteira como traficante. Dessa maneira, o jornalista mantém a protagonista na condição de vítima, utilizando partes da denúncia apresentada pelo MP-GO. Para legitimar essa condição, a voz utilizada no texto é do órgão público que fez a denúncia, o MP-GO, como na sentença "elas foram abordadas de surpresa, por viatura policial que já as aguardava no local do evento". 
Segundo Resende e Ramalho (2019) "a seleção das vozes nessa recontextualização, bem como as maneiras como elas são representadas, diz muito sobre o posicionamento político desse evento discursivo na rede de práticas sociais" (p.100). Nessa articulação entre informação apresentada e o posicionamento do órgão denunciador, somado ao texto produzido pelo jornalista, podemos compreender a intertextualidade, pois o autor, em seu texto, responde a outros textos, articulando vozes legitimadas, como as de agentes da Polícia Federal e do Ministério Público.

Quanto à materialidade linguística dos comentários produzidos a partir da notícia postada, em geral são caracterizados pela mescla entre linguagem escrita e visual, produzindo multimodalidade por meio da grafia escrita digital e da representação gráfica (emoji), bem como pelo recurso do hiperlink, citando e direcionando a resposta para outros usuários inscritos na plataforma.

Do total de comentários, é possível observar uma distribuição de 91 comentários $(40,81 \%)$ referentes ao próprio texto fonte, configurando-se um comentário direto, e 132 comentários $(59,19 \%)$ emergidos dos comentários em forma de réplica e tréplica, o que equivale a um comentário indireto. Santos $(2018$, p. 28) salienta que, nessa esfera de comunicação, as "relações de interação são muito dinâmicas e diversificadas", "o que implica diferentes destinos para as réplicas".

É importante lembrar que, no Instagram, nem sempre o comentário indireto evidencia uma resposta à manifestação anteriormente comentada. Dinamicamente, pode se usar a resposta de um comentário para chamar a atenção de qualquer outro usuário para uma resposta dada ou mesmo para comentar a notícia, utilizando um local que supostamente não estaria adequado para se fazer a marcação.

O quadro a seguir mostra a autoria dos comentários gerados em torno da notícia distribuída por gênero. Do total analisado, distribuídos à luz do critério de autoria por sexo, sem levar em consideração se houve repetição de um mesmo comentador ao longo do debate, chegamos à seguinte disposição de comentários:

Quadro 1

Quantidade de comentários distribuída por autoria corpo-política do
\begin{tabular}{|c|c|c|}
\hline Masculino & Feminino & Anônimo \\
\hline 120 & 77 & 26 \\
\hline Total & \multicolumn{2}{|c|}{223} \\
\hline \multicolumn{3}{|c|}{} \\
\hline
\end{tabular}

Fonte: os autores (2021)

Quanto aos turnos de comentários, podemos observar que estampam, em sua maioria, o perfil de um comentador do sexo masculino, contrariando o senso comum de que "mulheres falam demais". Curiosamente, dos 132 comentários indiretos, 67 deles $(50,76 \%)$ correspondem a réplica e tréplica masculina, restando a porcentagem a ser distribuída ao grupo feminino e de anônimos. Essa proporção se alinha à dos comentários diretos, em sua maior parte, também realizados por homens $(58,43 \%)$. 
Acerca do conteúdo discursivo, boa parte dos comentários masculinos mobiliza itens lexicais que denotam agressividade e firmeza em posicionamento, alguns utilizando caixa alta, de modo a inferir deselegância na etiqueta virtual, já que invadem o comentário alheio para atacá-lo ou mesmo ironizá-lo em forma de réplica e tréplica.

[CDM] Policiais despreparados são tão normais hoje em dia! Passam dos $60 \%$ (45 curtidas)

[CIM] preparada tava a difunta , traficante e péssima mãe , essa sim tava preparada.....preparada pro mal..... foi tarde demais.... (15 curtidas)

Em geral os comentários femininos, talvez devido ao volume de adesão e de identificação com a vítima mulher ou com o tema da maternidade balizado na notícia, estão sob o nível de solidariedade e deferência. Nesse sentido, é possível inferir um endosso de sororidade em forma de comentários em relação ao campo semântico do tema "mãe-morta" noticiado.

[CDF] Fico pensando como as pessoas são capazes de julgar e condenar outras que não conhecem, baseado em declarações de policiais que muitas vezes são piores que bandidos, lamentável (0 curtidas)

Diante das ações discursivas materializadas corpo-politicamente por diferentes internautas que comentam sobre um fato entre si, uma reflexão de Borba $(2014$, p. 7) torna-se fulcral, na tentativa de avaliarmos, no caso, o mundo virtual de significados em telas, no qual vivemos, por intermédio exclusivo da potencialidade performativa da linguagem.

tudo que um sujeito faz (sua moral, sua ética, sua estética corporal, seus gostos, seus desejos, suas ambições, seus modos de falar, de olhar, de andar, de sonhar, de amar...) é expressão de um "eu" autônomo, de uma essência que a priori molda o sujeito e suas ações e serve de centro organizador de sua subjetividade. (BORBA, 2014, p. 7)

Não podemos - e nem seria necessário - saber com presteza de quem se trata o comentador em si, isto é, de sua identidade. No mundo virtual, os discursos que enredam um comentário on-line, ainda que marcados por uma intencionalidade, por si só nos fornecem pistas daquilo que se torna mais relevante sociopragmaticamente: as ideologias e subjetividades postas/publicadas. São elas, em suas configurações qualitativas, que, tornadas públicas, darão volume, consenso, adesão e/ou intensidade para as devidas significações em redes sociais.

Diante do fazer linguístico estrutural e estruturante, resta-nos problematizar: que subjetividades estão sendo construídas ou d/enunciadas em nosso mundo on-line, a partir de nossas publicações? Considerando que algo é dito por pessoas e que esse enunciado dos comentadores não apenas constitui sua identidade, não apenas representa uma negociação de sentidos, todavia corresponde à própria atuação sobre o mundo virturreal por intermédio da linguagem (AUSTIN, 1990), que comentários estamos fazendo em redes?

Por outro lado, embora em plataformas digitais, como menciona Entringer (2018), geralmente faça parte da política de produção de comentários possuir um perfil logado, a 
quantidade de comentários anônimos ${ }^{2}$ indicou um número relativamente alto dentro do contexto analisado $(11,66 \%)$, abrindo espaço para se questionar as devidas motivações. Proporcionalmente, são comentários que possuem maior volume de caracteres digitados e, em alguns casos, argumentação mais bem formulada, utilizando-se, para tanto, uma retórica manejada por competência linguística e por exemplificações, e argumentos de autoridade ou históricos, sejam a favor ou contra a vítima.

De qualquer modo, não podemos negar que, em um contexto virtual brasileiro alavancado pela violência e pela polaridade política, materializado por discursos de ódio (BIAR, 2020), por violência linguística (SILVA, 2019) e por fake news, sejam muitas as justificativas e intencionalidades para que um perfil pessoal de uma página de Instagram não seja revelado publicamente.

Na política dos comentários, tivemos a mesma percepção de Entringer (2018), em seu estudo, a respeito da ausência de argumentação consistente em defesa do ponto de vista por parte dos comentadores. Um aspecto relevante, e também identificado por Biar (2020), é que, além de beirar o senso comum, boa parte dos comentários sobre a notícia analisada se abastece de ideologias que movimentam a polaridade política existente no Brasil na contemporaneidade, bem como, em nosso caso, o domínio discursivo religioso-cristão.

Encontramos, ainda, em meio aos sentidos abrangidos pelos comentários que abastecem o diálogo, o desnível do comentário, veiculando a chamada de um terceiro leitor à participação ou mesmo comentando sobre um tópico de tendência (trending topic) sobre o qual, àquele momento, não caberia vazão, por não levar em consideração o tópico do texto referência.

O aleatório dos comentários também se situa nas respostas desencaixadas e de dúvida para quem elas estão sendo direcionadas, fato que, de maneira indireta, reflete no caráter de opacidade da linguagem escrita. No entanto, aludindo a Foucault (2012, p. 25, grifos do autor), o comentário acaba por "dizer enfim o que estava articulado silenciosamente no texto primeiro". Transforma, como disse, "o aleatório do que foi dito - aquilo que surge a partir do discurso e que não havia sido previsto ou pensado antecipadamente - em parte constituinte do próprio discurso" (p. 25).

Por fim, saltam aos olhos duas inter/discursividades que orbitam os comentários, classificadas em: 1) a morte como punição para o crime cometido e 2) a depreciação da vítima diante das circunstâncias da ocorrência policial. Essa taxonomia veio à tona com o conteúdo argumentativo recorrente nos comentários, bem como com o fazer linguístico da prática de comentar: as curtidas prevaleceram sobre os comentários que significaram a congratulação à ação policial e/ou que depreciaram a figura feminina morta.

\section{A MORTE COMO PUNIÇÃO PARA O CRIME COMETIDO}

2 Consideramos anônimos os comentadores dos quais não foi possível precisar a identificação, devido 1) à inexistência de uma imagem corpóreo-facial do perfil comentador, em alguns casos intencionalmente para não se ter a identidade pública revelada, ou 2) a não se tratar de um perfil de acesso público e, com isso, não conseguirmos depreender, em visita ao perfil e a conteúdos produzidos (feed), qual a suposta corporalidade reivindicada, ou 3) a se tratar de perfis comerciais, os quais, ao invés de publicarem rostos, estampam a imagem da empresa ou os produtos à venda, tornando-se impossível definir a propriedade de autoria corpo-política. 
$24,66 \%$ dos comentários justificaram a morte da mulher como consequência de ela ter praticado o suposto crime de tráfico de drogas. Os comentários em torno desse núcleo derivam de pessoas que não enxergam a gravidade na ação praticada pela polícia, de maneira a incidir na morte da mulher.

[CDF] Era uma pessoa tão boa que foi buscar drogas levando o filho. (72 curtidas)

Cercado por relações de poder, o direito da confeiteira à vida é sequer cogitado pelos internautas, violando, assim, princípios preconizados na Declaração Universal dos Direitos Humanos (ONU, 1948).

[CIA] defendemos e vamos continuar defendendo a polícia, que está $24 \mathrm{hrs}$ batendo de frente com a criminalidade! É difícil acreditar que tem gente que regente uma traficante que leva dois menos de idade para buscar encomenda né?! Lamentável!!!! (2 curtidas)

[CDM] Sem discutir o mérito, quem envolve-se com drogas, quer seja: usuário, traficante ou mulas, só tem pela frente velas e morte, nada mais. Uma pena, uma jovem trabalhadora e mãe, ser executada friamente. (3 curtidas)

Chamam-nos a atenção as contas anônimas, as quais, durante as postagens em observação, em geral, utilizam uma linguagem mais adequada à norma padrão, com argumentos mais contundentes e coesos, em termos de comentários, seja em apoio à vítima ou em apoio à ação policial. Em se tratando do comentário anônimo anterior, o usuário o faz como comentário indireto, em resposta a uma crítica negativa sobre a abordagem dos policiais envolvidos, e, logo abaixo do próprio comentário, corrige a palavra "regente" por "defende".

Como escreve a notícia, a ação policial teve como resultado a morte da vítima, que, por sua vez, não esboçou reação ou mesmo revidou o confronto policial, o que justificaria uma legítima defesa dos militares envolvidos. Os comentadores desse núcleo, no caso, escamoteiam o fato de que, diante de tal situação, a ação policial prudente seria a de uma abordagem para prender a confeiteira. Refutam, pois, princípios legais e constitutivos estabelecidos em favor da ampla defesa da vítima, para atribuírem valor e apoio à ação policial $(6,73 \%)$ ou apreço à categoria militar $(3,14 \%)$. Os argumentos para esses posicionamentos são provenientes de faces masculinas.

[CDM] O ministério público não cansa de defender vagabundos. A pmgo fez foi um belo trabalho em prol da sociedade. $\square$ (7 curtidas)

Considerando a máxima de que um indivíduo só é considerado culpado após condenação transitada em julgado, o comentário a seguir faz menção à presunção de inocência dos policiais, que estão sendo denunciados por homicídio e tentativa de homicídio.

[CDM] Denúncia e uma coisa.Trânsito em julgado e outra , todo mundo e inocente ate que se prove o contrário mídia desprezível. (2 curtidas) 
O ponto fulcral é que a morte, nos comentários em tela, é colocada sob o desígnio de validar a punição de uma pessoa em conflito com a lei e, não raras vezes, é naturalizada a perda da vida como castigo para satisfazer a justiça social perante uma prática ilícita, seja ela de que grau e sob que circunstância for. Escapa-se, grosso modo, do ideal legal da prisão, visando à alternativa socioeducativa e, posteriormente, à possibilidade de reinserção social/ressocialização.

Nutrida pela apatia, talvez ocasionada pelo distanciamento promovido pela virtualidade, boa parte dos internautas - do sexo masculino -, grosso modo, honra os policiais denunciados pelo Ministério Público e esmaece o mérito de vida à confeiteira sob alegação de que estaria comprando droga para venda. Em outras palavras, a perda da vida é consequência do ato de tráfico ou, como discutiremos a seguir, por não estar cumprindo seu papel de mãe esperado pela sociedade, ao estar acompanhada de seu filho na prática do suposto crime.

\section{A FIGURA FEMININA EM UM CONTEXTO MACHISTA, MISÓGINO E PATRIARCAL}

A condição feminina da confeiteira, que também é mãe e mulher, é um tema que emerge dos comentários no contexto de análise e também é promulgado visualmente em seu aspecto discursivo-corpóreo, por intermédio da imagem-capa que abre a chamada para a notícia on-line. Nesse caso em específico, acena para um problema social mais amplo: o de gênero. Vejamos dois comentários:

[CDF] Confeiteira não, traficante! Tem que trocar o título dessa matéria. (1 curtida)

$[\mathrm{CDM}]$ Tem que trocar o "confeiteira" por TRAFICANTE. $\square \square \square \square \square$. (1 curtida)

De um lado, ocorrem insatisfações inerentes às referenciações postas pelo redator, o qual, primando pela ética jornalista, não pode substantivar ou adjetivar alguém com autoria de crime até então suposta. Em outras palavras, significa dizer que, antes de uma averiguação e comprovação da justiça, para uma ética jornalística, sem comprovação jurídica do fato, não se pode nomear a mulher como traficante, como assim querem alguns internautas.

[CDF] Ok! Os policiais erraram no procedimento, mas a matéria vir amenizar a moça dizendo "confeiteira", a mulher e uma traficante MUITO cruel que teve a capacidade de levar ainda DUAS crianças com ela para buscar as drogas. (3 curtidas)

[CDF] Matéria muito mal escrita, curuiz... Execução por parte dos PMs despreparados, ponto final.. duas mulheres e uma criança nao trocariam tiros c a PM... Maconha e armas "apareceram" no carro... Kkk. (3 curtidas)

[CDM] Confeiteira entrega é bolo e não drogas!!! Que bosta de matéria tendenciosa. (33 curtidas)

Alguns comentários denotam o confronto com o texto fonte, escrito pelo jornalista, na tentativa de rechaçar a qualidade linguística para a interpretação da matéria. Discursivamente, essa ação pode representar uma estratégia para tentar invalidar ou desvalo- 
rizar o posicionamento da redação do jornal, a qual, por sua vez, certamente informou o assunto da perspectiva apresentada pelo Ministério Público. É possível observar o uso jornalístico de presunções valorativas e de argumentos de autoridade, de referenciação da profissão (confeiteira) e do uso da palavra "encomenda", em substituição a "tabletes de maconha", fornecendo pistas textuais que inferem a inocência da vítima.

O estereótipo apresentado nos comentários parece ser também uma espécie de nomeação que reduz o corpo eletrônico, destituído de afeto e de conhecimento interlocutor, a um meme, incluindo, nesse conceito de imagem ou nas descrições grafadas que criam, na identidade da imagem, uma insignificância humanitária. É mais do que a estilização corporal que, em repetição, produz algo; é, sobremaneira, a redução da experiência de um corpo levada a uma exclusiva categoria que limita potencialidades de sua existência, um artifício discursivo muito comum e preocupante em ambientes virtuais. Caberia ainda o questionamento se essa seria uma manifestação pejorativa ocorrida em prejuízo de ser endereçada a uma mulher.

$12,11 \%$ dos comentários justificaram a ação violenta policial devido à protagonista da trama ter banalizado o seu papel de mãe. A condição desse mau exemplo é recuperada em alguns comentários que subjugam a figura feminina e valorizam a atuação dos agentes públicos.

[CDF] Mais como uma mãe tem a capacidade de ir buscar maconha pra vender e levar o filho? Pior que a matéria fala como se ela tivesse ido buscar uma encomenda de bolo algo assim! (108 curtidas)

Por outro lado, $17,45 \%$ dos comentários foram a favor da vítima, o que, diante de uma polaridade nefasta em nosso contexto, significa rejeitar o extremo de se criticar a ação, por tabela, não apoiar a PM. A tônica é que os comentários de apoio à mulher vítima entoam discursos que levam em conta a vida e o direito humano de pagar pelo crime sem pena de morte. Boa parte dos comentários que integra esse núcleo endossa a truculência policial e destaca o mau exemplo de atuação profissional; curiosamente, são os que possuem menos curtidas:

[CDF] Tenho certeza que se fosse ao contrário,o caso já teria sido encerrado . Claro ,Fabiana presa! Que à Justiça de Deus seja feita . $\square$. (0 curtidas)

[CDM] Conheço a família, ela foi fazer entrega de bolo, ela era confeiteira msm, os polícias confundiram o carro dela, sem preparo nenhum chegou já atirando contra o veiculo $\square$ lógico que eles tinham que dá um argumento né, realmente tem polícias preparados mas em compensação a esses tais que agem por impulso $\square$. (17 curtidas)

[CDF] Essa é a versão dos policiais, não está se encaixando só faltaram dizer que tevê troca de tiros. (0 curtidas)

[CIM] condecorações por matar uma pessoa e colocar a vida de uma criança em perigo? Tá Serto . Se ela errou teria que pagar na justiça . Policial não pode fazer justiça com as próprias mãos. Totalmente despreparado esses policiais . No máximo vão ficar presos no quartel tendo todas as regalias é sustentados pelo 
estado . Com certeza vão inventar uma troca de tiros e uma história mentirosa que nunca existiu . Lamentável ... (1 curtida)

Não obstante, a comoção tem gênero e a sororidade, assim, se manifesta em forma de fazer discursivo (SILVA, 2019) sob o argumento de má conduta policial, em virtude da condição desfavorável da mulher ao reagir à abordagem. Em suma, o público feminino, talvez por alguma identificação, foi o que mais realizou, com a ação de comentar, a compaixão e o repúdio à ação policial noticiada no texto jornalístico. Os comentários nessa dimensão apontam a agressão policial e clamam ainda pela urgência de uma investigação mais apurada sobre a veracidade dos fatos denunciados.

\section{COMENTAR ON-LINE É UM ATO DE LINGUAGEM}

Em paralelo às defesas dos envolvidos na trama, como vimos, houve comentários que se situaram na depreciação da qualidade de compreensão leitora de redação da notícia. Sem necessariamente mencionar de que lado estavam, é possível deduzir, pelo próprio agir da linguagem, que ideologias e fazeres discursivos (SILVA, 2019) estariam previstos ao criticarem, aleatoriamente, aspectos de má escrita do texto jornalístico. Assim sendo, esses comentários, cujo desnível solidário (FOUCAULT, 2012) abrangido destoa perceptivelmente do foco temático da notícia, levando em conta seus autores, teriam outras intencionalidades, como abrir espaço proposital para outras disputas de sentido?

Esse exame minucioso da prática discursiva não precisa ser especializado para compreender que, nas tomadas de posição, indicativas da intencionalidade do interlocutor, um texto de referência a um comentário pode ter apenas um de seus fios de significação perseguido e d/enunciado. Quem comenta escolhe as entrelinhas para, a partir da tangência interpretativa, agir intencionalmente no mundo. Pode ser que a intenção, ao se criticar o conteúdo do texto jornalístico, seja exclusivamente a de punir a mulher. De qualquer modo, tudo isso nos leva a crer que, em turnos de comentários gerando um debate, o posicionamento interlocutor abre pragmaticamente espaço para novos posicionamentos, remetendo a outras características acionais discursivas e promovendo novas ações.

Diante da notícia on-line evidenciada nesta pesquisa, pairaram sobre os dedos da opinião pública o julgamento, a condenação e a exclusão virtual de corpos semióticos - algumas vezes reduzidos a memes - envolvidos em circunstâncias, as quais, muitas vezes, são lidas sem criticidade, isto é, de uma única perspectiva de interpretação, quando não mal lido o texto. São por esses motivos que pessoas passam a ser injustamente condenadas, canceladas, e o pior: têm na formação discursiva posta o ideário exercido em sociedade.

Contudo, há vida por trás das telas repleta de sentimentos, histórias, mundividência, inferiorizada ou rotulada, de acordo com nossos posicionamentos discursivos, os quais borbulham exclusivamente da leitura que fazemos de um fato ao comentá-lo, sem chances de ter versões ampliadas e lidas. A propósito, quem não pecou que faça o primeiro comentário! 
O comentador on-line muitas vezes se blinda por uma tela (computador ou smartphone) e faz escolhas linguísticas, tendo a seu favor: 1) o distanciamento físico interlocutor, 2) o lapso entre a produção e a leitura do comentário por um terceiro, algumas vezes causado pelo formato assíncrono da tecnologia utilizada, 3) o não comprometimento da face perante o interlocutor, 4) a universalização do dito sem ofensa personalizada, 5) a tranquilidade de nem sempre ter que se preocupar em rastrear a repercussão de seu dito em rede. Por se tratar de um espaço de manifestação pública, entretanto, há algumas regras que devem ser respeitadas ao agir pela linguagem por meio dos comentários.

\section{CONSIDERAÇÕES FINAIS}

Ainda que se constitua, em analogia à metáfora empregada por Entringer (2018, p. 30), uma "praça pública", onde se "prevalece a livre interação, sem fronteiras definidoras entre falante e ouvinte(s)", a manifestação de ideias por meio de comentários deve primar por ética, alteridade e empatia com o/s outro/s. Ainda que as garantias legais estejam dispersas, e algumas vezes desconhecidas por quem usa a Internet, é urgente refletir sobre o que estamos fazendo ao comentar on-line: comprometendo ou cancelando vidas, colaborando para um mundo insensível e desigual à diferença. $\mathrm{O}$ comentário agressivo virtual, que reflete outras práticas sociais promovidas diariamente, muitas vezes direcionado a alguém, por exemplo, fere a dignidade humana, causando sérios prejuízos aos envolvidos.

Além disso, temos, com a manifestação livre de ideias sobre determinado fato, colaborado para o quê? Qual o impacto dessa prática na sociedade que temos hoje? Ao internauta cabe a sensibilidade crítica de fazer um escrutínio do que interpreta e do que comenta, e, mais ainda, compreender a serviço de que ou quem determinado comentário e interpretação estão, caso entendamos que agimos no mundo por meio dos comentários em rede.

\section{REFERÊNCIAS}

AUSTIN, John Langshaw. Quando dizer é fazer. Tradução de Danilo Marcondes de Souza Filho. Porto Alegre: Artes Médicas, 1990.

BARTON, David. Understanding textual practices in a changing world. In: BAYNHAM, Mike; PRINSLOO, Mastin. (Org.). The future of literacy studies. Houndmills: Palgrave Macmillan, 2009. p. 38-53.

BIAR, Liana de Andrade. "(Não) Leia os comentários": a disputa da notícia sobre o assassinato de Marielle Franco. Trabalhos em Linguística Aplicada, Campinas, v. 59, n. 2, p. 1051-1069, 2020.

BORBA, Rodrigo. A linguagem importa? Sobre performance, performatividade e peregrinações conceituais. Cadernos Pagu, v. 43, p. 441-474, 2014.

BRASIL. Marco Civil da Internet (Lei no 12.965/2014) é a principal fonte a ser utilizada nesta questão. Disponível em: <http://www.planalto.gov.br/ccivil_03/_ato2011-2014/2014/lei/112965.htm> Acesso: 10 abr. 2021.

CINTRA, Reinaldo Silva. O discurso do ódio sob uma teoria performativa da linguagem. $92 \mathrm{f}$. Monografia (Bacharelado em Direito) - Pontifícia Universidade Católica, Rio de Janeiro, 2012.

CUNHA, Dóris de Arruda C. da. Reflexões sobre o ponto de vista e a construção discursiva de comentários de leitores na web, Revista Investigações, v. 25, n. 2, p. 21-41, 2012.

ENTRINGER, Ângela Almeida Nascimento. Ensino e prática da argumentação em comentário on-line: uma 
proposta para as séries finais do ensino fundamental II. 117 f. Dissertação (Mestrado Profissional em Letras) Instituto Federal do Espírito Santo, Vitória, 2018.

FAIRCLOUGH, Norman. Discurso e mudança social. Brasília: Universidade de Brasília, 2001.

FAIRCLOUGH, Norman. Language and globalization. Abingdon: Routledge, 2006.

FOUCAULT, M. A ordem do discurso. Trad. Laura Fraga de Almeida Sampaio. São Paulo: Edições Loyola, 2012.

KÖCHE, Vanilda Salton; MARINELLO, Adiane Fogali; BOFF, Odete Maria Benetti. Leitura e produção textual: gêneros textuais do argumentar e expor. Petrópolis, Rio de Janeiro: Vozes, 2017.

MAGALHÃES, Izabel. Protagonismo da linguagem: textos como agentes. Revista Brasileira de Linguística Aplicada, v. 17, n. 4, p. 575-598, 2017.

MERCURI, Karen Tank; LIMA-LOPES, Rodrigo Esteves de. Discurso de ódio em mídias sociais como estratégia de persuasão popular. Trabalhos em Linguística Aplicada, Campinas, SP, v. 59, n. 2, p. 1216-1238, 2020.

ONU. Assembleia Geral das Nações Unidas. Declaração Universal dos Direitos Humanos. 1948. Disponível em $<$ https://www.unicef.org/brazil/declaracao-universal-dos-direitos-humanos> Acesso em 19 mar. 2021.

RESENDE, Viviane de Melo; RAMALHO, Viviane. Análise de Discurso Crítica. São Paulo: Editora Contexto, 2019.

SAL PAZ, Julio César. Comentário digital: género medular delas prácticas discursivas de la cibercultura. Caracteres: Estudios culturales y críticos de la esfera digital, v. 2, n. 2, p. 152-172, 2013.

SANTOS, Eliane Pereira dos. O gênero comentário online: um enfoque axiológico-dialógico do estilo. 257 f. Tese (Doutorado em Letras) - Universidade Federal de Pernambuco, Pernambuco, 2018.

SILVA, Danilo da Conceição Pereira. (Meta)pragmática da violência linguística: patologização das vidas trans em comentários online. Trabalhos de Linguística Aplicada, Campinas, v. 58, n. 2, p. 956-985, 2019. 